Article

\title{
A New System of Sustainable Silico-Aluminous and Silicate Materials for Cultivation Purpose within Sustainable Buildings: Chemical-Physical, Antibacterial and Cytotoxicity Properties
}

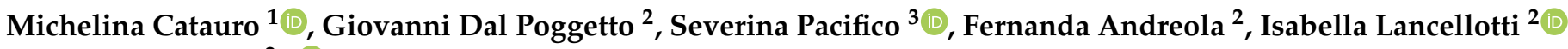 \\ and Luisa Barbieri ${ }^{2, *}$ (D) \\ 1 Department of Engineering, University of Campania “Luigi Vanvitelli", Via Roma 29, I-813031 Aversa, Italy; \\ michelina.catauro@unicampania.it \\ 2 Department of Engineering “Enzo Ferrari”, University of Modena and Reggio Emilia, 41125 Modena, Italy; \\ giovanni.dalpoggetto@unimore.it (G.D.P.); fernandanora.andreola@unimore.it (F.A.); \\ isabella.lancellotti@unimore.it (I.L.) \\ 3 Department of Environmental, Biological and Pharmaceutical Sciences and Technologies, University of \\ Campania “Luigi Vanvitelli”, via Vivaldi 43, 81100 Caserta, Italy; severina.pacifico@unicampania.it \\ * Correspondence: luisa.barbieri@unimore.it
}

check for updates

Citation: Catauro, M.; Dal Poggetto, G.; Pacifico, S.; Andreola, F.; Lancellotti, I.; Barbieri, L. A New System of Sustainable

Silico-Aluminous and Silicate Materials for Cultivation Purpose within Sustainable Buildings: Chemical-Physical, Antibacterial and Cytotoxicity Properties. Appl. Sci. 2022, 12, 434. https://doi.org/ 10.3390/app12010434

Academic Editor: Muhammad Junaid Munir

Received: 6 December 2021 Accepted: 29 December 2021 Published: 3 January 2022

Publisher's Note: MDPI stays neutral with regard to jurisdictional claims in published maps and institutional affiliations.

Copyright: (c) 2022 by the authors. Licensee MDPI, Basel, Switzerland. This article is an open access article distributed under the terms and conditions of the Creative Commons Attribution (CC BY) license (https:// creativecommons.org/licenses/by/ $4.0 /)$.

\begin{abstract}
In this study, we compared the chemical-physical, antibacterial, and cytotoxicity properties of silico-aluminous and silicate materials for outdoor (green roof, planted walls) and indoor (urban farms, indoor microgreen gardens) cultivation purpose in a context of sustainable construction. Glasses and lightweight aggregates were tailored starting from waste, by-product, and post-consumer and bioproducts (packaging glass cullet, cattle bone flour ash, vegetable biomass ash, spent coffee ground, degreased from biomass of prepupae of Black Soldier Flies) mixed together with a national ferruginous red clay, quarry scrap pumice and, if necessary, with $\mathrm{K}_{2} \mathrm{CO}_{3}$ of reagent grade. The first type of material was obtained by melting at $1200{ }^{\circ} \mathrm{C}$ and the second one by powder sintering at $1000{ }^{\circ} \mathrm{C}$. All specimens, subjected to antibacterial test, showed both low zone of inhibitions towards two Gram-negative and two Gram-positive bacterial strains. A cytotoxicity test on mouse embryonic fibroblast NIH-3T3 cell line directly exposed to the investigated materials was performed at three different exposure times $(1 \mathrm{~h}, 3 \mathrm{~h}$, and $6 \mathrm{~h}$ ). Data acquired highlighted that the materials positively affected redox mitochondrial activity of the fibroblast cells. The concentrations of leachate heavy metals detected on selected materials in water at room temperature after $24 \mathrm{~h}$ were lower than the European law limit and an interesting release of $\mathrm{P}, \mathrm{K}$, and $\mathrm{N}$ nutrients was noted for those formulations designed for agronomic purposes. $\mathrm{pH}$, falling on average within the 6.5-7.5 range, is optimal for most crops, and the specific conductivity $<2 \mathrm{dS} / \mathrm{m}$ indicates no depression danger for crops. Both bulk density $<1200 \mathrm{~kg} / \mathrm{m}^{3}$ and porosity over $50 \%$ seem to ensure good performance of lightening, drainage, water reservation, and oxygenation of the roots.
\end{abstract}

Keywords: lightweight aggregates; residues utilization; antibacterial properties; cytotoxicity properties; sustainable buildings

\section{Introduction}

Thinking both with a view to sustainable buildings and to the evolution we have been witnessing in recent years as a result of issues such as climate change, pandemics, and the need to increase the productivity of the neighboring area, we cannot fail to consider issues such as hanging gardens and indoor cultivation.

We talk about hanging gardens if you want to create a plant system on a waterproof structural support layer, such as concrete slabs, attics, wooden roofing, and metal roofing, and in all those cases in which there is no ecological continuity between the green and the subsoil up to the mother rock [1]. Hanging gardens can be extensive or intensive. The 
former are non-walkable green roofs that need minimal maintenance and an irrigation system that comes into operation only in the hottest periods; intensive hanging gardens, on the other hand, are walkable and require a deep substrate, an adequate irrigation system, and can accommodate fountains, trees, and even swimming pools. Hanging gardens play an important role in sustainable construction and environmental quality of buildings, bringing benefits in economic and environmental terms. The roof used as a garden helps to control the temperature and to reduce pollution. It contributes to create thermal insulation on summer air conditioning and winter heating with consequent savings in the energy management of the building. Moreover, thanks to chlorophyll photosynthesis, hanging gardens produce oxygen and reduce the amount of $\mathrm{CO}_{2}$ in the atmosphere. In addition, the hanging gardens retain rainwater and reduce the phenomenon of urban heat islands. In other words, a green roof keeps all the technological and construction content typical of a traditional roof reproducing, in addition, the typical performance of a natural soil covered with vegetation, to a complete or limited extent. It can therefore be considered a compensation and mitigation tool for the impacts generated by the inclusion of new structural works in the territory, suitable for generating the formation of near-natural ecosystems in densely built-up areas [1]. The hanging garden must not be considered as a simple finishing and should not be applied as an ordinary building material, because this means not considering plants as living and complex organisms in dynamic and continuous evolutionary equilibrium with the external environment and in need of maintenance.

The indoor cultivation technique allows you to grow any type of plant inside a closed environment, such as a grow box, a greenhouse, or a room, where all the stages of development and growth of the plant take place, from germination to flowering. Some advantages of indoor over outdoor cultivation are:

- it is possible to control the whole crop, including the temperature, the time of exposure of plants to light, and when the plant will receive water;

- gives year-round cultivation regardless of season;

- it is possible to harvest more quickly since in an indoor crop gives to control the photoperiod of the plants;

- less exposure to pests or other bugs;

- it is a zero-kilometer technique;

- it allows the saving of more than $90 \%$ of water compared with traditional crops;

- $\quad$ any space can be used: just have the accessories and assemble your own grow;

- by having space, it is also possible to place multiple overlapping indoor crops (the so-called vertical farms);

- there is no dependence on sunlight, but it is necessary to have a suitable kit of lights that can recreate the optimal growth atmosphere for plants. Many also use the most modern LED lamps to decrease production costs.

The 2020 World Population Data Sheet indicates that the world population is projected to reach nearly 10 billion by 2050, and the corresponding projection of the increase in food production is $70 \%$ compared with $25 \%$ in 2014 [2]. In the face of this, it is likely that there will not be a similar increase in land use for agricultural purposes (primarily cereals) if we consider that over almost 60 years, from 1961 to 2018, in a context of growth of almost $240 \%$ of cereal production and around $145 \%$ of the population, there was an increase in land use for cereals of only almost $12.5 \%$ [3]. Moreover, drought and soil salinity are the main factors responsible for reducing yield.

Additionally, the COVID-19 pandemic has negatively impacted traditional agriculture due to border closures, quarantines, and disruptions to supply chains. From this picture emerges the need both to increase crop productivity and to have it nearer by using innovative approaches, and indoor farming could be a significant help.

In this context, chemical-environmental parameters such as $\mathrm{pH}$, conductivity, leaching of heavy metals, antibacterial properties, and cytotoxicity become of primary importance for those materials engineered for the applications described and which involve an important handling, with possible storage and use in confined environments. 
The $\mathrm{pH}$ is a scale of measurement of the acidity or basicity of an aqueous solution, while the electrical conductivity is directly linked to the presence of salts in solution, the dissociation of which generates positive and negative ions which are responsible for the transport of electrical energy when the solution is subjected to an electric field. They are both constitute very important data since the agricultural purpose for which the manufactured products are destined requires that values of these quantities are respected so as not to interfere with the growth of plants. A material intended for crops must in fact have a $\mathrm{pH}$ as close as possible to neutrality in order to be compatible with almost all plants. Agricultural soils considered neutral have $\mathrm{pH}$ values ranging between 6.8 and 7.3 , and in them the absorption of nutrients is maximized. In general, the widest acceptable range for plants is that which goes from 5.5 to 8.5; for values beyond these, they would hardly be able to adapt.

The measurement of electrical conductivity, on the other hand, is used to determine the presence of salts in the soil by measuring their presence in the saturated aqueous extract taken from it. The weak point of this technique, however, is the ability to indicate the quantity but not the quality of the salts present, being a non-specific parameter. Indeed, it is not possible to know whether it is given by a useful salt, such as calcium nitrate, or by a harmful one, such as sodium chloride. In general, however, too high conductivity values are dangerous for plants because the greater presence of salts implies greater difficulty in the absorption of water by the root system of plant organisms. Conductivity is expressed in $\mathrm{dS} / \mathrm{m}$, referring to the saturated extract of the soil. Ideal values for each type of crop are those that do not exceed $2 \mathrm{dS} / \mathrm{m}$, while the danger of crop depression increases up to $4 \mathrm{dS} / \mathrm{m}$. Beyond this value, any type of crop, even the most tolerant, risks deterioration. The tests carried out are regulated by the UNI EN 13037: 2012 (pH) (“UNI EN 13037" 2012) and UNI EN 13038: 2012 (conductivity) (“UNI EN 13038” 2012) standards. The relationship between soil and water in the extraction determines how much the salts contained in the soil are diluted in the water and therefore the EC value. The result can therefore be evaluated only by knowing the extraction ratio. The most commonly used extractions in Italy are: saturated pasta (impractical execution and not always used), the ratio 1:2 (soil/water), and the ratio 1:5 (soil/water).

The effect of heavy metal pollution on plant organisms induces a stressful condition, and thus influence the processes of growth, development, and productivity. Plants present articulated and dynamic systems of response to stimuli from stresses that are more complex than those found in animals. The fundamental reason of this is that plants are sessile organisms, i.e., they do not have the possibility of moving away from the region in which the stress occurs, and therefore they cannot escape from life-threatening conditions [4]. Abiotic stresses (temperature, drought, salinity, heavy metals) arise from the establishment of an excess or lack of chemical and physical factors that determine the characteristics of the environment in which the plant lives. Biotic stresses are caused by other living organisms, e.g., pathogens.

Antibacterial and cytotoxicity tests represent two tools for establishing if a material is inert or stable and are very important parameters in particular for porous materials capable to adsorb (and release, also) different substances and organisms. In particular, the dermal contact of new materials thought to be in contact with humans and animal should be taken into account to ward off potential adverse effects.

Finally, other important parameters, especially for substrate for hanging gardens, are light weight, high water retention capacity, and enough aeration capacity; therefore, density, porosity, and water absorption can give an idea in this sense.

This study represents the evolution of previous research aimed at the engineering of materials (glasses and lightweight aggregates) based on waste from the agro- and postconsumer sector, some of which having fertilizing properties. Active glasses and ceramic lightweight aggregates with controlled release of NPK macronutrient have been created and described in previous works [5-12]. In addition, total particulate emissions during 
heat treatment and carbon footprint have been assessed for some aggregates compositions, and the encouraging results described in a previous paper [13].

In view of the applications mentioned and on the background of the authors, in this research, the results of the physical-chemical-environmental parameters briefly described above were reported together with the description of new formulations of lightweight aggregates obtained increasing the amount of recovery raw materials with a view to "circularity", through the use of quarry scrap pumice (a volcanic mineral, naturally expanded and naturally light, which is rich in Italy).

The final output is represented by performant products such as density, porosity, $\mathrm{pH}$, and specific conductivity, fully characterized in terms of leaching of heavy metals, antibacterial, and cytotoxicity properties.

\section{Materials and Methods}

\subsection{Starting Materials and Mixtures}

Among the different raw materials selected, only two were conventional virgins: a local ferruginous (around $8 \mathrm{wt} \%$ of $\mathrm{Fe}_{2} \mathrm{O}_{3}$ ) red clay (used as ceramic matrix for lightweight aggregates) and reagent grade $\mathrm{K}_{2} \mathrm{CO}_{3}$ (put in some compositions as potassium carrier). The other are residues, post-consumer products, or sub-products. Packaging glass cullet or quarry scrap pumice were used as vitrifying agents in the realization of glasses or ceramic aggregates. Spent coffee grounds (SCG), thanks to their high LoI, $98 \%$, and with a C content around $50 \mathrm{wt} \%$ were used as pouring agent for aggregates; cattle bone flour ash (41 wt $\%$ of $\left.\mathrm{P}_{2} \mathrm{O}_{5}\right)$ and vegetable biomass ash $\left(60 \mathrm{wt} \%\right.$ of $\mathrm{K}_{2} \mathrm{O}$ ) (in some case this last substituted by reagent grade $\mathrm{K}_{2} \mathrm{CO}_{3}$ ) were considered alternative raw materials for the supply of the two main nutrients, phosphorus and potassium, respectively. The third main nutrient, nitrogen, was applied on a selected composition of aggregate using an organic nitrogenbased coating (average $\mathrm{N}$ content ranging from 8 to $9 \mathrm{wt} \%$ ) extracted from black soldier fly (BSF) prepupae reared on poultry dejections and compared to a commercial organic nitrogen fertilizer of blood derivation. The volcanic scrap (pumice) is a natural porous silico-aluminous mineral containing $57 \mathrm{wt} \% \mathrm{SiO}_{2}$ (determined by XRF analysis, here not reported), and it is a good substituent of local clay as a silicon source. The mineralogical analysis highlighted that only a small amount of $\mathrm{SiO}_{2}$ is in the crystalline phase constituted by sanidine (11\%), quartz (1\%), anorthite (3\%), muscovite $(4 \%)$, and traces of feldspathoids, the rest is in the composition of the amorphous phase $(80 \%)$. A deep characterization of the other raw materials was provided in the previous publication of the authors [12].

Two series of samples were prepared and studied: the first constituted by glasses and the second by aggregates, as shown in Table 1. Three glasses (FG1, FG2, and FG3) were obtained by melting in electric furnace at $1450{ }^{\circ} \mathrm{C}$, varying both the vitrifying component (packaging glass cullet or pumice scrap) and the potassium carrier (reagent grade $\mathrm{K}_{2} \mathrm{CO}_{3}$ or vegetable biomass ash), but keeping fixed the introduction of $\mathrm{P}_{2} \mathrm{O}_{5}$ in the form of cattle bone flour ash. All the fertilizer glasses produced were tailored to have the following amounts of the main oxides: $\mathrm{SiO}_{2}(30-32 \mathrm{wt} \%), \mathrm{Al}_{2} \mathrm{O}_{3}(1-4 \mathrm{wt} \%), \mathrm{K}_{2} \mathrm{O}(\sim 15 \mathrm{wt} \%), \mathrm{Na}_{2} \mathrm{O}$ ( $\sim 6 \mathrm{wt} \%), \mathrm{CaO}\left(24-26 \mathrm{wt}^{\mathrm{t}} \%\right), \mathrm{MgO}(\sim 1.50 \mathrm{wt} \%), \mathrm{P}_{2} \mathrm{O}_{5}(\sim 15 \mathrm{wt} \%)$.

Eight aggregates were tailored and obtained by fast powder sintering at $1000{ }^{\circ} \mathrm{C}$. A first series was constituted starting from a formulation of $85 \mathrm{wt} \%$ of clay and $15 \mathrm{wt} \%$ of spent coffee grounds alone (C) and addition of $50 \mathrm{wt} \%$ of $\mathrm{P}, \mathrm{K}$ nutrients vitrified by packaging glass cullet (CFG2) or non-vitrified (CNUT2). A second series was represented by aggregates of half part of clay and half part of pumice (volcanic inert) for a total of $85 \mathrm{wt} \%$, plus $15 \mathrm{wt} \%$ of spent coffee grounds alone (CP) and addition of $50 \mathrm{wt} \%$ of $\mathrm{P}, \mathrm{K}$ nutrients vitrified by pumice scrap (CPFG3) or non-vitrified (CPNUT3). Finally, a third series was represented by the specimens with half part of clay and half part of pumice as matrix and FG3 glass and coated by a nitrogen-containing layer of degreased from biomass of soldier fly prepupas (CPFG3N1) compared to a commercial product based on animal blood (CPFG3N2). 
Table 1. List of samples and their composition.

\begin{tabular}{|c|c|}
\hline Sample Code & Composition \\
\hline FG1 & Fertilizer glass (packaging glass cullet $+\mathrm{K}_{2} \mathrm{CO}_{3}+$ cattle bone flour ash $(\mathrm{P})$ ) \\
\hline FG2 & $\begin{array}{l}\text { Fertilizer glass (packaging glass cullet }+ \text { vegetable biomass ash }(\mathrm{K})+\text { cattle bone flour } \\
\text { ash }(\mathrm{P}))\end{array}$ \\
\hline FG3 & Fertilizer glass (pumice scrap $+\mathrm{K}_{2} \mathrm{CO}_{3}+$ cattle bone flour ash $(\mathrm{P})$ ) \\
\hline $\mathrm{C}$ & LWAs (clay + spent coffee grounds) \\
\hline CFG2 & LWAs (clay + spent coffee grounds) + FG2 \\
\hline CNUT2 & LWAs (clay + spent coffee grounds) + nutrients of FG2 non-vitrified \\
\hline $\mathrm{CP}$ & LWAs (clay/pumice + spent coffee grounds) \\
\hline CPFG3 & LWAs (clay/pumice + spent coffee grounds) + FG3 \\
\hline CPNUT3 & LWAs (clay/pumice + spent coffee grounds) + nutrients of FG3 non-vitrified \\
\hline CPFG3N1 & $\begin{array}{l}\text { LWAs (clay/pumice }+ \text { spent coffee grounds) + FG3 with nitrogen-based coating } \\
\text { extracted from black soldier fly }\end{array}$ \\
\hline CPFG3N2 & $\begin{array}{c}\text { LWAs (clay/pumice }+ \text { spent coffee grounds) }+ \text { FG3 with commercial } \\
\text { nitrogen-based coating }\end{array}$ \\
\hline
\end{tabular}

\subsection{Chemical-Physical Parameters}

Being that the glasses are non-porous materials with a high degree of sintering, density and porosity were evaluated on LWAs only, and in particular limiting the analysis of specimens without coating.

The total porosity (TP) was calculated from the apparent and absolute densities values according to the formula:

$$
\mathrm{TP}=100 \times(\rho \mathrm{ab}-\rho \mathrm{ap}) / \rho \mathrm{ab}
$$

where $\rho a p=$ apparent density was determined by an envelope density analyzer (GeoPyc 1360, Micromeritics, Norcross, GA 30093, USA), using a dry medium, while $\rho a b=$ absolute density was determined by a gas (He) pycnometer (AccyPy1330, Micromeritic, Norcross, GA 30093, USA).

The good performance regarding soil and growing plants of all the materials obtained were assessed by measuring the $\mathrm{pH}$ and electrical conductivity. For the measurements, performed on all the formulations apart the specimens coated (for operational problems as the tests are carried out under agitation and the coating can be removed), the specific rules that indicate to use a solid/liquid ratio (1:5) using distilled water were followed. After $1 \mathrm{~h}$ of stirring at $360 \mathrm{rpm}$, the liquid was separated by filtration. The determinations were carried out on the filtrate.

The $\mathrm{pH}$ was measured by using a pHmeter (XS Instruments, pH 6, Carpi (MO), Italy), according to EN 13037 (2011) standard [14] and the electrical specific conductivity (ESC) was measured by a conductimeter (Thermo Scientific Eutech Instruments, COND6, Breda, Holland) according to the EN 13038 (2011) standard [15].

\subsection{Leaching Test}

The ability of leaching heavy metals was carried out according to the UNI EN 124572:2004 [16]. Samples, crushed and sieved to particle sizes less than $4 \mathrm{~mm}$, were placed in bi-distilled water with $10 \mathrm{~L} / \mathrm{kg}$ liquid/solid weight ratio, and maintained for $24 \mathrm{~h}$. After the extraction and filtration of the leachates, samples were acidified with $\mathrm{HNO}_{3}$ solution to $\mathrm{pH}=2$. Then, according to UNI EN ISO 11885:2009 [17], ion's heavy metal concentrations were determined by ICPE (ICPE-9000 Shimadzu, Tokyo, Japan).

The evaluation of total $\mathrm{K}$ was performed by EPA 2018 Method 6010D [18], while, to evaluate $\left(\mathrm{NO}_{3}\right)^{-}$and $\left(\mathrm{PO}_{4}\right)^{3-}$ release, APAT CNR IRSA 4020 Man 292003 [19] was used. Finally, total P and total N were determined by APAT CNR IRSA 4110 [20] by UNI EN 12260:2004 [21], respectively. 
This kind of analysis was limited to the three kind of glasses in order to test a possible influence of the different raw materials (mainly of recovery), and, with regard to LWAs, to the family with a highest amount of residues into the matrix (clay and pumice scrap) and as layer on the surface (i.e., the $\mathrm{N}$-containing coating and coming from biomass of soldier fly prepupa or animal blood).

\subsection{Antibacterial Activity}

Preliminary information about antibacterial properties of materials were obtained through the Kirby-Bauer test.

Escherichia coli (ATCC 25922) and Pseudomonas aeruginosa (ATCC 27853) as gramnegative bacteria (-) and Staphylococcus aureus (ATCC 25923) and Enterococcus faecalis (ATTC 29212) as gram-positive bacteria (+) were growth in the absence and presence of samples. Materials used for analysis were finely ground, $100 \mathrm{mg}$ of weight, and were radiated by UV light for $1 \mathrm{~h}$ for sterilization. The bacterial suspension of $10^{9} \mathrm{CFU} / \mathrm{mL}$ was obtained by diluting the strains in distilled saline water $\left(9 \mathrm{~g}\right.$ of $\mathrm{NaCl}$ in a liter of $\left.\mathrm{dH}_{2} \mathrm{O}\right)$. E. coli was plated on TBX Medium (Tryptone Bile X-Gluc) (Liofilchem, Roseto degli Abruzzi, Italy), S. aureus on Baird-Parker agar (Liofilchem, Italy), P. aeruginosa on Pseudomonas CN Agar, and finally E. faecalis on Slanetz Bartley agar base. All media, except for the Slanetz-Bartley agar base, were sterilized up to $120^{\circ} \mathrm{C}$ for $15 \mathrm{~min}$.

After the sterilization process, Baird-Parker agar was cooled to $50{ }^{\circ} \mathrm{C}$ and an emulsion of egg yolk containing potassium tellurite was added. A CN pseudomonas supplement was added to Pseudomonas CN Agar when it was cooled to $45^{\circ} \mathrm{C}$.

As also reported in [22], the powders were directly placed in the middle of Petri dishes after bacteria plating. The E. coli plates were incubated at $44^{\circ} \mathrm{C}$ for $24 \mathrm{~h}$ while those of $E$. faecalis and P. aeruginosa at $36^{\circ} \mathrm{C}$ for $48 \mathrm{~h}$. Finally, S. aureus plates were incubated at $36{ }^{\circ} \mathrm{C}$ for $24 \mathrm{~h}$. The diameter of inhibition zones (IDs) in relation to Petri dish diameter (PPD) $(6 \mathrm{~cm})$ were calculated. Four measures for each sample were carried out to determine the mean Standard Deviation. The whole procedure was sketched in the flow-chart shown in Figure 1.

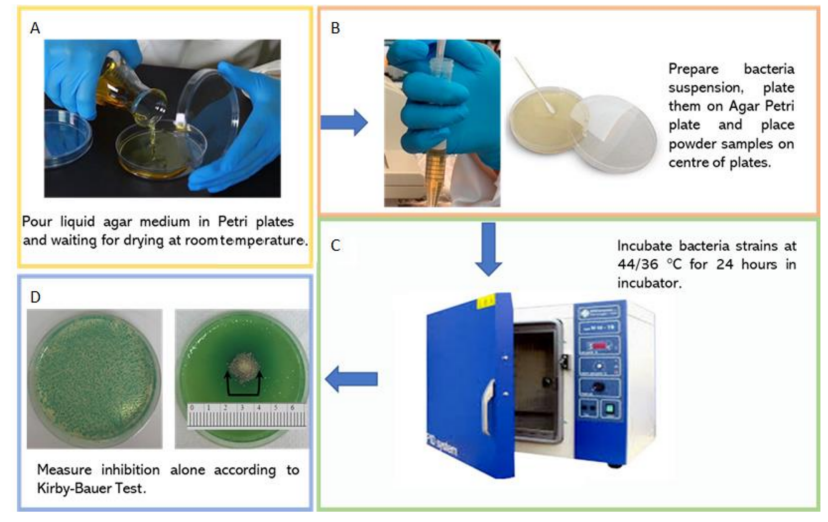

Figure 1. Flow-chart of antibacterial detection.

This test was performed on all the formulations, considering a possible handling and storage even in confined and domestic environments according to the possible uses described in the introductory part.

\subsection{Cytotoxicity}

MTT assay was used to determine the metabolic activity on NIH-3T3 murine fibroblast cells. To this purpose, cells were grown in Dulbecco's Modified Eagle Medium supplemented with $10 \%$ fetal bovine serum, $50.0 \mathrm{U} / \mathrm{mL}$ penicillin, and $100.0 \mu \mathrm{g} / \mathrm{mL}$ streptomycin at $37{ }^{\circ} \mathrm{C}$ in a humidified atmosphere containing $5 \% \mathrm{CO}_{2}$. Cells were seeded at a density equal to $5.0 \times 10^{5}$ per well, onto 6 -well plates, and then directly exposed to the synthesized material (1 mg). After 1, 3, and $6 \mathrm{~h}$ of incubation, cells were treated with MTT 
$(500 \mu \mathrm{L} ; 0.50 \mathrm{mg} / \mathrm{mL})$, previously dissolved in culture media, for $2 \mathrm{~h}$ at $37{ }^{\circ} \mathrm{C}$ in a $5 \%$ $\mathrm{CO}_{2}$-humidified atmosphere. The MTT solution was then removed, DMSO was added to dissolve formazan, and the absorbance was read at $570 \mathrm{~nm}$ using a Victor3 Perkin Elmer fluorescence and absorbance reader. The cell viability was expressed as a percentage of mitochondrial redox activity of the cells directly exposed to the synthesized materials, in respect to unexposed control. Similarly, to what was written in the previous paragraph, this parameter was also tested on all formulations.

\section{Results and Discussion}

\subsection{Chemical-Physical Parameters}

\subsubsection{Density and Porosity}

On the basis of the EN 13055:2016 rule [23], a material can be defined as lightweight aggregates (LWAs) if the density is lower than 2.0 g. $\mathrm{cm}^{-3}$. The LWAs obtained with the formulations reported in Table 1 fall into this category. The experimental data showed density values between 1-1.5 g.cm ${ }^{-3}$. Comparing the compositions, those containing pumice in partial substitution of clay were always lighter (lower density and higher porosity). The trend indicates an increase in density when nutrients are present and again when they are vitrified. This is explained by the fact that the ashes and the fertilizer glass present in the mixture have a fluxing role during the sintering and contribute to the final densification.

In Figure 2 the correlation between the apparent density and the total porosity for the LWAs analyzed is plotted. Correlation may be described as the degree of association between the two variables considered. It is possible to note an inverse proportionality: increasing apparent density decreases the porosity. It is possible to verify the goodness of the experimental data by the correlation coefficient: $\mathrm{R}^{2}=0.9378$. Besides, the regression highlights a linear relationship. The porosity values ranged between $40 \%-60 \%$, and, as referred above, the lighter materials were more porous.

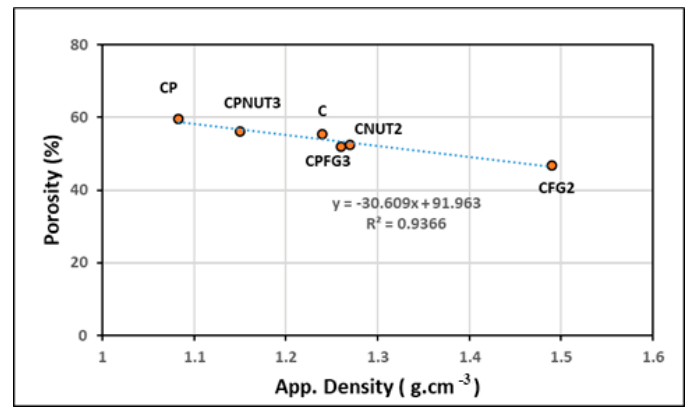

Figure 2. Correlation between Porosity vs. App. Density for the LWAs prepared.

\subsection{2. $\mathrm{pH}$ and Electrical Conductivity}

An important requirement for the use of material in indoor cultivation or hanging garden is the $\mathrm{pH}$ between 6.5 and 8 , which is the optimal range that would make it compatible with most plant species.

In Figure 3 the $\mathrm{pH}$ values measured both in an aqueous extract of fertilizer glasses and LWAs are plotted. It can be noted that all glasses compositions displayed $\mathrm{pH}$ values higher than those corresponding to LWAs. The glasses compositions were properly designed by the authors to achieve a controlled release over time of $\mathrm{P}$ and $\mathrm{K}$ and to use them to functionalize LWAs with a specific percentage of $\mathrm{K}$ and $\mathrm{P}$ as required by the Italian legislation on fertilizers [24]. It is possible to hypothesize that since the glasses contain high percentages of $\mathrm{K}(12 \%)$ and $\mathrm{Ca}(26 \%)$, the release of these elements clearly involves alkaline $\mathrm{pH}$ values. Regarding the LWAs samples, all compositions showed $\mathrm{pH}$ values within the optimal interval (6.5-8). The highest value corresponded to the CFG2 composition containing the addition of $50 \%$ of fertilizer glass. 


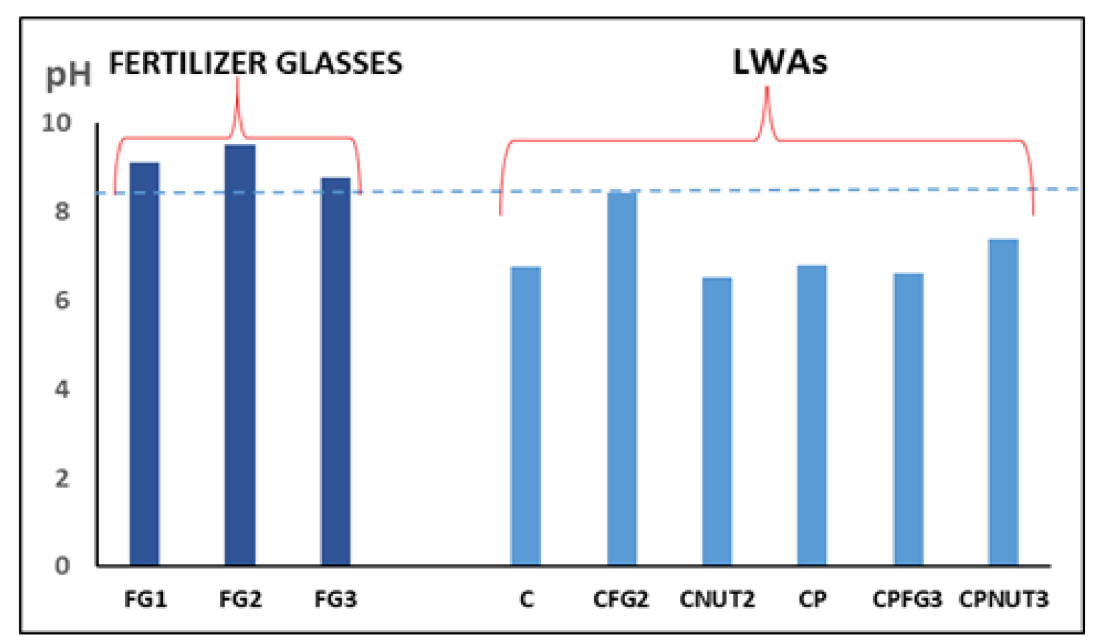

Figure 3. $\mathrm{pH}$ measured on eluates from fertilizer glasses and LWAs obtained.

Concerning electrical conductivity (EC), all manufactured materials were within the appropriate range for growing plants $(0.2-2 \mathrm{dS} / \mathrm{m})$, as shown in Figure 4 . It is noteworthy that CNUT2 composition showed the highest EC value, since it contained ashes as source of $\mathrm{P}$ and $\mathrm{K}$ nutrients with high presence of $\mathrm{Ca}$ and $\mathrm{Mg}$ oxides, so the mobility of ions was elevated in solutions. Different behavior was shown by CNUT3's composition, which contains the non-vitrified nutrients, but the K source was potassium carbonate.

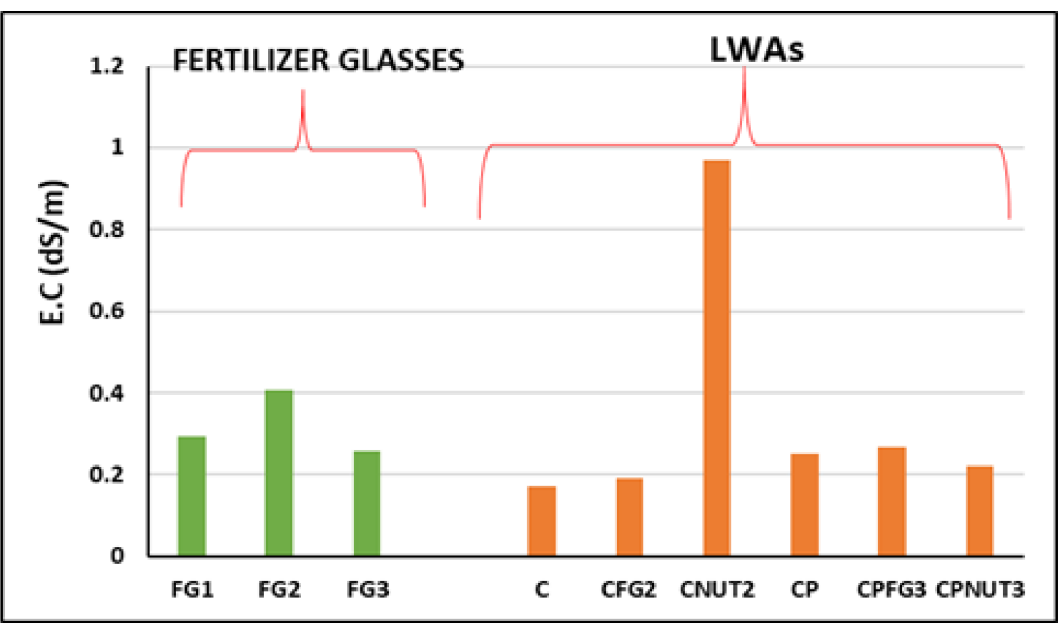

Figure 4. EC measured on the fertilizer glasses and LWAs obtained.

\subsection{Leaching Test}

Results about the type and the quantity of metals released from the samples are summarized in Table 2. FG1, FG3, CPFG3, CPFG3N1, and CPFG3N2 were the samples with the highest amount of $\mathrm{Al}$ released, while FG1, CPFG3, and CPFG3N2 released the highest amounts of Fe. All the other heavy metals were in traces. The results are in accordance with [18]; indeed, all the data were lower than the Law limits. The release results of $\mathrm{P}, \mathrm{N}$, and $\mathrm{K}$ are reported in Table 3. 
Table 2. Results of metals release expressed in $\mathrm{ppb}$.

\begin{tabular}{|c|c|c|c|c|c|c|c|}
\hline \multirow{2}{*}{ METALS } & \multicolumn{7}{|c|}{ SAMPLE } \\
\hline & FG1 & FG2 & FG3 & CPFG3 & CPNUT3 & CPFG3N1 & CPFG3N2 \\
\hline $\mathrm{Al}$ & 484.62 & 114.58 & 634.1 & 960.1 & 69.52 & 203.08 & 120.3 \\
\hline As & 10.66 & 11.04 & $<2$ & $<2$ & 5.3 & 5.95 & 54.2 \\
\hline B & 115.72 & 199.79 & 60.4 & 153.2 & 4.94 & 3.92 & 160.4 \\
\hline $\mathrm{Ba}$ & $<2$ & $<2$ & $<2$ & $<2$ & $<2$ & $<2$ & $<2$ \\
\hline Be & $<2$ & $<2$ & $<2$ & $<2$ & $<2$ & $<2$ & 2.9 \\
\hline $\mathrm{Cd}$ & $<2$ & $<2$ & $<2$ & $<2$ & $<2$ & $<2$ & $<2$ \\
\hline Co & $<2$ & $<2$ & $<2$ & $<2$ & $<2$ & $<2$ & $<2$ \\
\hline $\mathrm{Cr}$ & 11.54 & 5.21 & $<2$ & 12,85 & $<2$ & 3.82 & $<2$ \\
\hline $\mathrm{Cu}$ & 4.64 & 3.69 & 4.1 & 4.43 & $<2$ & $<2$ & $<2$ \\
\hline $\mathrm{Fe}$ & 244.92 & 70.22 & 39.84 & 154.3 & 13.76 & 2.94 & 161.6 \\
\hline Mn & 5.34 & 4.58 & $<2$ & 22,4 & $<2$ & $<2$ & 47.8 \\
\hline Mo & $<2$ & 2.26 & $<2$ & 31.64 & $<2$ & 12.9 & 225.21 \\
\hline $\mathrm{Ni}$ & 39.31 & 39.23 & 9.47 & 5.7 & $<2$ & $<2$ & 7.67 \\
\hline $\mathbf{P b}$ & $<2$ & 2.82 & $<2$ & 10.1 & $<2$ & $<2$ & 3.45 \\
\hline $\mathrm{Sb}$ & 9.18 & 10.79 & 2.6 & 5.79 & 2.02 & $<2$ & 6.09 \\
\hline Se & 2.24 & $<2$ & $<2$ & $<2$ & $<2$ & $<2$ & 7.49 \\
\hline Sn & 10.39 & 4.8 & 2.13 & 16.62 & 3.24 & 7.02 & $<2$ \\
\hline $\mathrm{Tl}$ & $<2$ & 2.33 & 2.66 & 23.5 & 4.55 & 2.22 & $<2$ \\
\hline V & 24.01 & 11.02 & 63.1 & $>400$ & 40.77 & 65.39 & 62.99 \\
\hline $\mathrm{Zn}$ & 18.14 & 17.92 & 6.83 & 13.32 & $<2$ & 4.53 & 6.03 \\
\hline
\end{tabular}

Table 3. Results of nitrogen, phosphorus, and potassium released expressed in mg/L.

\begin{tabular}{|c|c|c|c|c|c|c|c|}
\hline & \multicolumn{7}{|c|}{ SAMPLE } \\
\hline & FG1 & FG2 & FG3 & CPFG3 & CPNUT3 & CPFG3N1 & CPFG3N2 \\
\hline $\mathrm{PO}_{4}{ }^{3-}$ & $<0.5$ & $<0.5$ & $<0.5$ & 0.741 & 0.821 & 2.41 & 7.1 \\
\hline P Tot & 0.543 & 0.672 & 0.966 & 2 & 2.5 & 130 & 23.1 \\
\hline $\mathrm{NO}_{3}{ }^{-}$ & - & - & - & - & - & 0.7 & 0.7 \\
\hline $\mathrm{N}$ tot & - & - & - & - & - & 9.516 & 1.672 \\
\hline K tot & 169.56 & 210.56 & 130.64 & 25.21 & 44.54 & 155.99 & 44.1 \\
\hline
\end{tabular}

As evidence, CPFG3N1 was the formulation with the highest release of these elements, respectively $130 \mathrm{mg} / \mathrm{L}$ of $\mathrm{P}, 9.52 \mathrm{mg} / \mathrm{L}$ of $\mathrm{N}$, and $156 \mathrm{mg} / \mathrm{L}$ of $\mathrm{K}$, followed by CPFG3N2 composition. On the other hand, FG1, FG2, and FG3 released high amounts of K.

\subsection{Antibacterial Activity}

The antimicrobial properties of the synthesized materials were investigated to validate their safety thanks to the ability to inhibit the growth of pathogenic bacterial strains according to Kirby-Bauer method (Figure 1D): the zone where no growth occurred is called the inhibition zone. Additionally, according to the Kirby-Bauer method, the bacterium is defined as resistant $(R)$ if the diameter of the inhibition zone is equal to or less than $17 \mathrm{~mm}$; intermediate (I) if the diameter is between 18 and $22 \mathrm{~mm}$; and sensitive (S) if it is equal to or greater than $23 \mathrm{~mm}$. No inhibition zone was observed for all samples tested with the four different strains. Samples tested were not able to release some bioactive molecules 
which can act as antimicrobial substances. On the other hand, powders of samples tested did not allow a proliferation of bacteria colonies on their surfaces. Indeed, the phenomena of adhesion between bacteria and material are a crucial step in the pathogenesis of these infections and this depends on many factors such as chemical composition of the material surface and its charge [25].

Figures 5-8 report the histograms relative to the inhibition zones expressed in $\mathrm{cm}$ after the incubation time with the four strains. All the samples showed no growths where they physically adhered to the Petri plates, leading to the inhibition zones with dimensions less than $17 \mathrm{~mm}$. According to the Kirby-Bauer method, the bacteria assayed are considered as resistant. This result is in agreement with what the authors found when testing tiles and glasses containing municipal bottom ashes in their composition [26]. Thus, the materials did not affect bacteria growth, which could be due to their ability to prevent bacteria attachment.

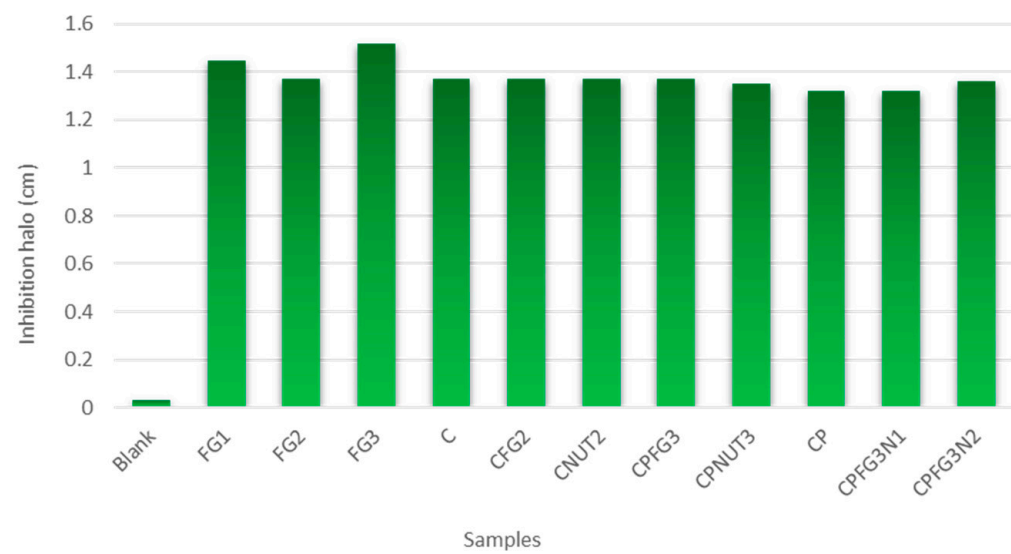

Figure 5. Inhibition zones of the samples tested in presence of E. coli (-).

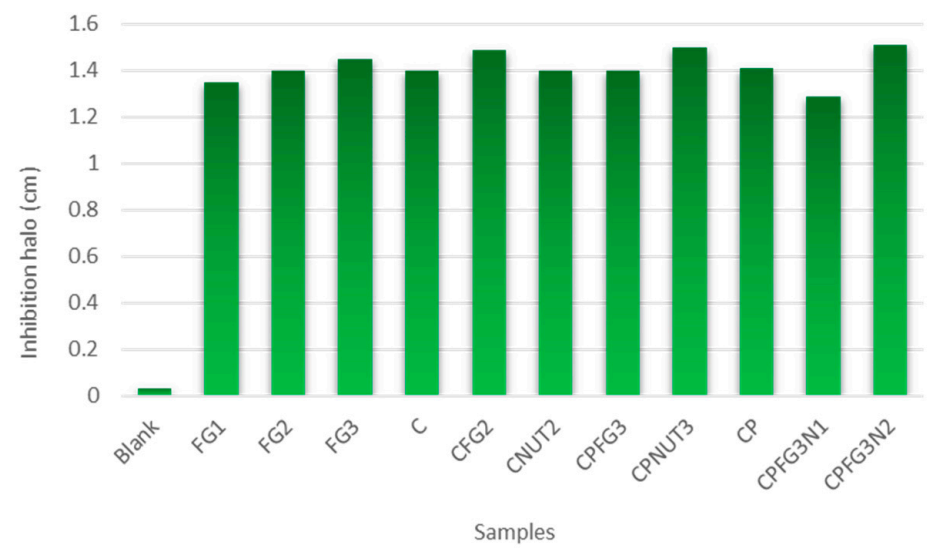

Figure 6. Inhibition zones of the samples tested in presence of S. aureus (+).

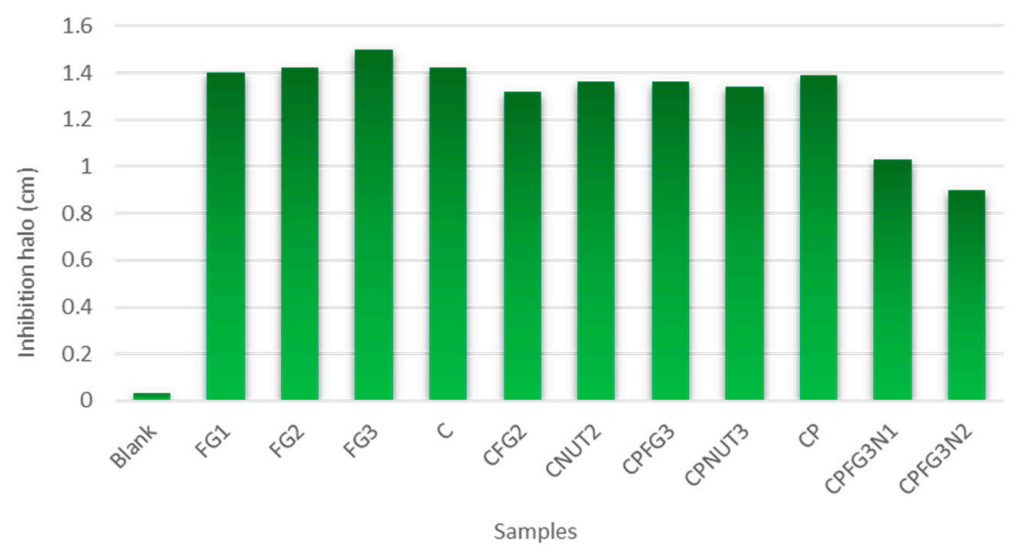

Figure 7. Inhibition zones of samples tested in presence of $P$. aeruginosa (-). 


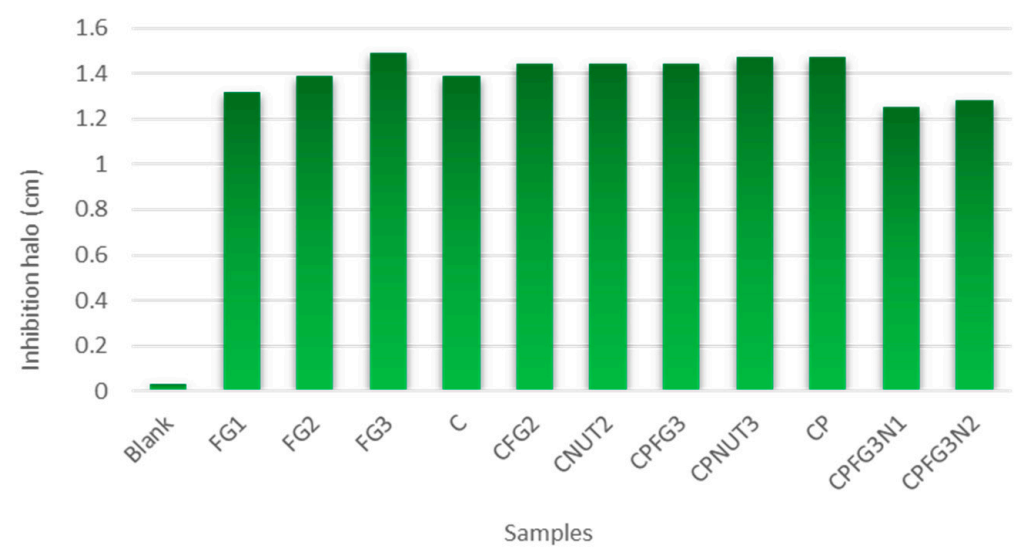

Figure 8. Inhibition zones of samples tested in presence of E. faecalis (+).

\subsection{Cytotoxicity}

The investigated materials underwent cytotoxicity screening in order to evaluate their safe effects for human and animal health. In this context, considering that the exposure of these materials could occur through the dermal contact, fibroblast NIH-3T3 cells were utilized, and MTT test were carried out at three different exposure times.

Data acquired evidenced that the materials, except CPNUT3, increased the redox mitochondrial activity of the tested cells time-dependently (Figure 9). CPNUT3 defined a weak inhibition of the activity, which was estimated as equal to $20 \%$, only at the lowest exposure time considered. Indeed, although inhibitory effects were not detectable through the colorimetric cell viability assay, changes in morphology were by microscope observation. In fact, the cells appeared to result in closely interlinked changes in their cell bulk properties (Figure 10). This behavior could be due to the weak cell contact among fibroblasts and the materials, so much so that they were found to spread randomly with spindle-like morphology. This is in line with the observation that the surface of the material directly in contact with cells affect their morphology [27], while not altering their mitochondrial redox activity.

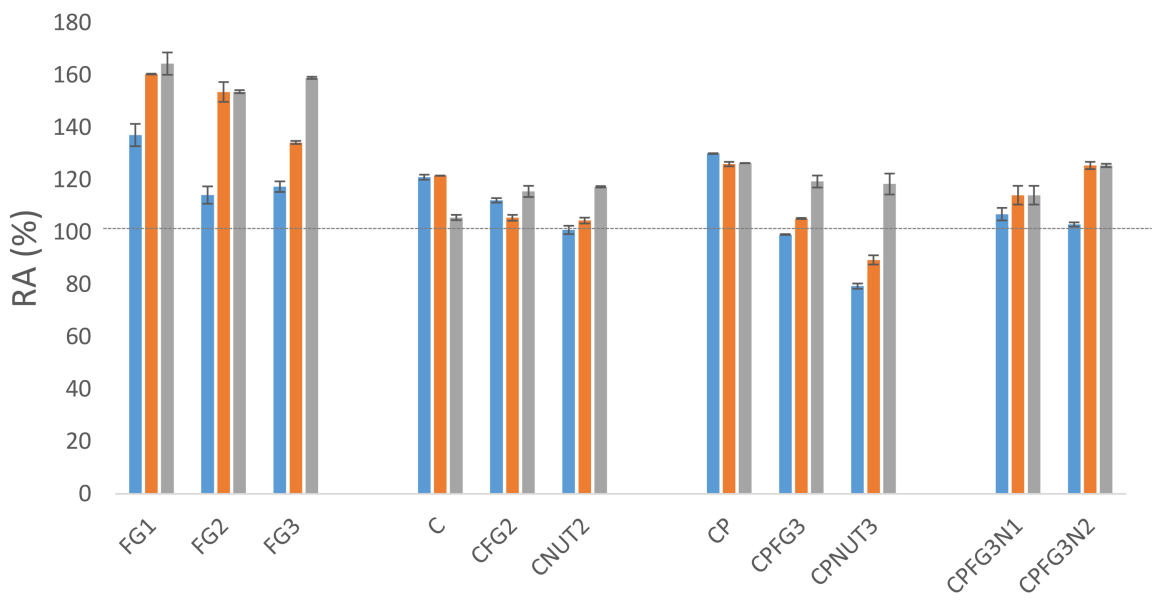

Figure 9. MTT data on NIH-3T3 redox mitochondrial activity (RA\%), acquired after the considered exposure's time $(1,3$, and $6 \mathrm{~h})$. The values are expressed as mean $\pm \mathrm{SD}$ of three of three independent measurements. 


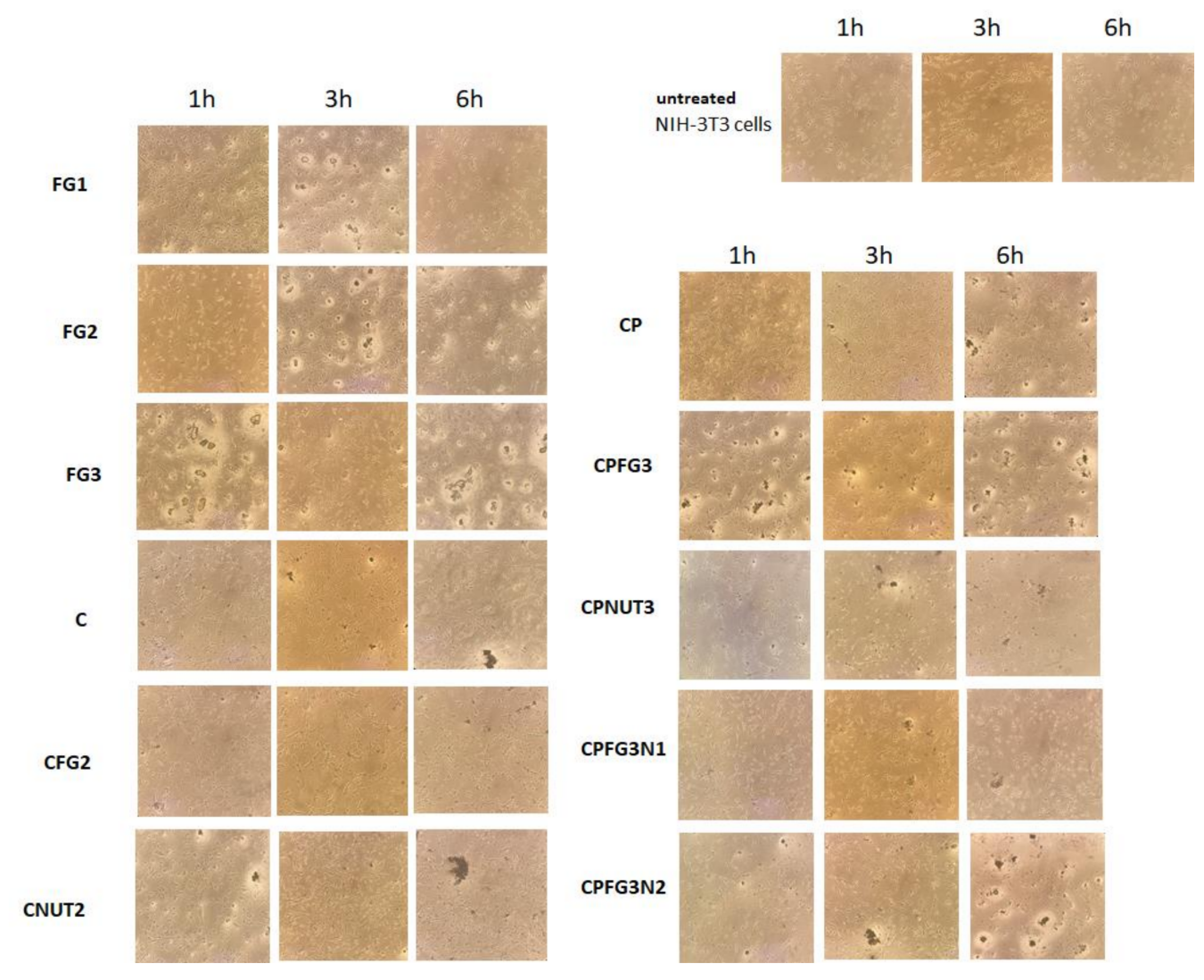

Figure 10. Representative images of untreated NIH-3T3 cells and investigated materials-treated NIH-3T3 cells, acquired by Inverted Phase Contrast Brightfield Zeiss Primo Vert Microscope at 1, 3 , and $6 \mathrm{~h}$ of exposure.

\section{Conclusions}

The preliminary laboratory results achieved in this study are very encouraging as they showed that the use of packaging glass cullet, cattle bone flour ash, vegetable biomass ash, spent coffee ground, degreased from biomass of prepupae of Black Soldier Flies, and volcanic scraps (pumice) in the production of fertilizer glasses and lightweight aggregates allows for obtaining sustainable ceramic materials without causing further impacts on humans and the environment. The leaching tests showed that $\mathrm{Al}$ is the element most solubilized, but it is in line with the release of a conventional clay in the ground while only traces of heavy metals are found. In agreement with Italian legislation, the materials obtained were not hazardous. Besides, it was demonstrated that the release of the main nutrients $(\mathrm{P}$, $\mathrm{K}, \mathrm{N}$ ) confirmed the feasibility to orient their use in outdoor or indoor cultivation purposes. Data acquired through cytotoxic assessment are in line with the synthesis of materials that are not harmful to human health through dermal contact, whereas antibacterial results highlighted the ability of the sintering and vitrification technologies to produce inert materials. Further analyses are needed to deeply unravel the ability of the synthesized materials to be resistant to bacteria attachment, as well as an in-depth study on the durability of materials over time.

Author Contributions: Conceptualization, L.B., I.L. and F.A.; formal analysis, G.D.P., S.P. and F.A.; data curation, M.C., G.D.P., S.P., F.A. and L.B.; writing-original draft preparation, L.B. and M.C.; writing-review and editing, L.B., S.P., I.L. and M.C.; supervision, L.B. All authors have read and agreed to the published version of the manuscript.

Funding: This research received no external funding.

Institutional Review Board Statement: Not applicable. 
Informed Consent Statement: Not applicable.

Data Availability Statement: No applicable.

Conflicts of Interest: The authors declare no conflict of interest.

\section{References}

1. ISPRA. Verde Pensile: Prestazioni di Sistema e Valore Ecologico, Manuali e Linee Guida; 78.3/2012; ISPRA: Roma, Italy, 2012; ISBN 978-88-448-0534-0.

2. Piesse, M. Global Food and Water Security in 2050: Demographic Change and Increased Demand, Future Directions International; Strategic Analysis Paper; Future Directions International: Nedlands, Australia, 2020; pp. 1-6.

3. Change in Cereal Production, Yeld and Land Use, World, 1961 to 2018, OWD Based on World Bank and UNI FAO. Available online: https: / / ourworldindata.org/grapher/index-of-cereal-production-yield-and-landuse?country= \{\}OWID_WRL (accessed on 10 October 2021).

4. Parrotta, L.; Guerriero, G.; Sergeant, K.; Cai, G.; Hausman, J.F. Target or barrier? The cell wall of early and later-diverging plants vs cadmium toxicity: Differences in the response mechanism. Front. Plant Sci. 2015, 6, 133. [CrossRef] [PubMed]

5. Barbieri, L.; Andreola, F.; Bellucci, D.; Cannillo, V.; Lancellotti, I.; Lugari, A.; Rincòn, J.M.; Romero, M.; Sola, A. Preliminary studies on the valorization of animal flour ash for the obtainment of active glasses. Ceram. Int. 2014, 40, 5619-5628. [CrossRef]

6. Farias, R.D.; Garcia, C.M.; Palomino, T.C.; Andreola, F.; Lancellotti, I.; Barbieri, L. Valorization of Agro-Industrial Wastes in Lightweight Aggregates for Agronomic Use: Preliminary Study. Environ. Eng. Manag. J. 2017, 16, 1691-1699. [CrossRef]

7. Andreola, F.; Borghi, A.; Pedrazzi, S.; Allesina, G.; Tartari, P.; Lancellotti, I.; Barbieri, L. Spent Coffee Grounds in the Production of Lightweight Clay Ceramic Aggregates in View of Urban and Agricultural Sustainable Development. Materials 2019, 12, 3581. [CrossRef] [PubMed]

8. Andreola, F.; Lancellotti, I.; Manfredini, T.; Barbieri, L. The circular economy of agro and post-consumer residues as raw materials for sustainable ceramics. Int. J. Appl. Ceram. Technol. 2019, 17, 22-31. [CrossRef]

9. Barbieri, F.; Barbi, S.; Andreola, F.; Lancellotti, I.; Garcia, C.M.; Palomino, T.C.; Montorsi, M.; Barbieri, L. Design and Characterization of Controlled Release pk Fertilizers from Agro-Residues. Environ. Eng. Manag. J. 2020, 19, 1669-1676. [CrossRef]

10. Barbi, S.; Barbieri, F.; Andreola, F.; Lancellotti, I.; Barbieri, L.; Montorsi, M. Preliminary Study on Sustainable NPK Slow-Release Fertilizers Based on Byproducts and Leftovers: A Design-of-Experiment Approach. ACS Omega 2020, 5, 27154-27163. [CrossRef] [PubMed]

11. Ronga, D.; Parisi, M.; Barbieri, L.; Lancellotti, I.; Andreola, F.; Bignami, C. Valorization of Spent Coffee Grounds, Biochar and other residues to Produce Lightweight Clay Ceramic Aggregates Suitable for Nursery Grapevine Production. Horticulturae 2020, 6, 58. [CrossRef]

12. Martínez-García, C.; Andreola, F.; Lancellotti, I.; Farías, R.; Cotes-Palomino, M.; Barbieri, L. Cleaner Design and Production of Lightweight Aggregates (LWAs) to Use in Agronomic Application. Appl. Sci. 2021, 11, 800. [CrossRef]

13. Barbieri, L.; Bigi, A.; Andreola, F.; Lancelotti, I.; Ghermandi, G.; Palomino, M.T.C.; García, C.M. Environmental impact estimation of ceramic lightweight aggregates production starting from residues. Int. J. Appl. Ceram. Technol. 2021, 18, 353-368. [CrossRef]

14. EN 13037:2011; Soil Improvers and Growing Media-Determination of pH. European Standard: Pilsen, Czech Republic, 2011.

15. EN 13038:2011; Soil Improvers and Growing Media-Determination of Electrical Conductivity. European Standard: Pilsen, Czech Republic, 2011.

16. UNI EN 12457-2:2004; Waste Characterization-Leaching Test-Conformity Test for Leaching of Granular Waste and SludgePart 2: One-Stage Test, with a Liquid/Solid Ratio of $10 \mathrm{~L} / \mathrm{kg}$, for Materials with Particles Smaller than 4 mm (with or without Reduction of Dimensions). European Standard: Pilsen, Czech Republic, 2011.

17. UNI EN ISO 11885:2009; Water Quality-Determination of Certain Elements by Inductively Coupled Plasma Optical Emission Spectrometry. European Standard: Pilsen, Czech Republic, 2011.

18. EPA 2018; Method 6010D (SW-846): Inductively Coupled Plasma-Atomic Emission Spectrometry. U.S. EPA: Washington, DC, USA, 2018.

19. APAT CNR IRSA 4020 Man 29 2003; Roma 2004Determination of Anions (Fluoride, Chloride, Nitrite, Bromide, Nitrate, Phosphate and Sulphate) by Ion Chromatography. Available online: https://www.arpal.liguria.it/images/stories/metodi_scarichi_rev01. pdf (accessed on 20 December 2021).

20. APAT CNR IRSA 4110; Analytic Methods for Water-Phosphorus (Orthophosphate; Total Phosphorus). Available online: http:/ / www.appa.provincia.tn.it/binary/pat_appa_restyle/tariffario/ElencoProveSL_19012016.1453198719.pdf (accessed on 20 December 2021).

21. UNI EN 12260:2004; Water Quality-Determination of Nitrogen—Determination of Bound Nitrogen (TNb) after Oxidation to Nitrogen Oxides. European Standard: Pilsen, Czech Republic, 2004.

22. Catauro, M.; D’Errico, Y.; D'Angelo, A.; Clarke, R.J.; Blanco, I. Antibacterial Activity and Iron Release of Organic-Inorganic Hybrid Biomaterials Synthesized via the Sol-Gel Route. Appl. Sci. 2021, 11, 9311. [CrossRef]

23. EN 13055:2016; Lightweight Aggregates. European Standard: Pilsen, Czech Republic, 2016.

24. Legislative Decree 29 April 2010, n. 75-Reorganization and Revision of the Regulations on Fertilizers (in Italian); Ministry of Agricultural, Food and Forestry Policies: Roma, Italy, 2010. 
25. Katsikogianni, M.; Missirlis, Y. Concise review of mechanisms of bacterial adhesion to biomaterials and of techniques used in estimating bacteria-material interactions. Eur. Cells Mater. 2004, 8, 37-57. [CrossRef] [PubMed]

26. Andreola, F.; Barbieri, L.; Soares, B.Q.; Karamanov, A.; Schabbach, L.; Bernardin, A.M.; Pich, C.T. Toxicological analysis of ceramic building materials-Tiles and glasses-Obtained from post-treated bottom ashes. Waste Manag. 2019, 98, 50-57. [CrossRef] [PubMed]

27. Zhang, X.; Aoyama, T.; Yasuda, T.; Oike, M.; Ito, A.; Tajino, J.; Nagai, M.; Fujioka, R.; Iijima, H.; Yamaguchi, S.; et al. Effect of microfabricated microgroove-surface devices on the morphology of mesenchymal stem cells. Biomed. Microdevices 2015, $17,116$. [CrossRef] [PubMed] 